\title{
Epi-aortic Doppler measurement of cardiac output in univentricular connection
}

\author{
Ad J J C Bogers' \\ Martin van den Burg',2 \\ Ronald Schepp ${ }^{2}$ \\ Jan Klein ${ }^{2}$ \\ 'Department of Cardiothoracic \\ Surgery; ${ }^{2}$ Department of \\ Anesthesiology, Thoraxcentre, \\ Erasmus University Medical Centre, \\ Rotterdam, The Netherlands
}

\begin{abstract}
Background: In the initial postoperative period after a Fontan-type operation for a univentricular circulation, cardiac output information is important, but cannot be provided by conventional methods due to the surgical reconstruction of the heart. In this regard we investigated the feasibility of epi-aortic Doppler measurements in order to calculate cardiac output.

Methods: Epi-aortic cardiac output measurement was compared with Fick measurements as the gold standard in eight patients with a univentricular circulation after a Fontan-type operation.

Results: The mean diameter of the aorta by epi-aortic measurement was $18 \mathrm{~mm}$ (range 14 to 25 ), by angiography $17 \mathrm{~mm}$ (range 10 to 24$)$, correlation coefficient $0.88(\mathrm{p}<0.05)$. The mean cardiac output by epi-aortic measurement was $2.81 . \mathrm{min}^{-1}$ (range 1.2 to 6.3 ), by the Fick calculations $1.81 . \mathrm{min}^{-1}$ (range 0.8 to 5.0 ). The correlation coefficient for cardiac output data in aortic diameters up to 20 millimeter in diameter was $0.55(\mathrm{p}<0.05)$.

Conclusions: Epi-aortic Doppler measurement of cardiac output after Fontan type reconstructions could be applied in aortas up to 20 millimeter in diameter. A reasonable correlation with Fick calculations was found. This was supported by Bland-Altman plotting. The method is intrinsically invasive, but application and removal of the device were easy and no complications related to the system were observed. An important restriction is the often present abnormal anatomy, either congenitally or after surgery.
\end{abstract}

Keywords: cardiac output, Fontan circulation, epi-aortic Doppler, extravascular Doppler

\section{Introduction}

Cardiac output measurement may be a useful tool in the care of patients in a critical condition. In this regard cardiac output measurement is often applied during and after cardiac surgery. Most frequently used is cardiac output measurement by Swan-Ganz catheter method. ${ }^{1,2}$ This technique is obviously not applicable in patients with univentricular circulation, in which the pulmonary circulation is not directly or exclusively supported by output from a subpulmonary ventricle, especially after a Fontan-type operation., Extravascular Doppler (EVD) or epi-aortic measurement of cardiac output in the pediatric age group was clinically introduced in $1999,5,6$ but has not met a widespread use, because of the intrinsic invasiveness of the method. In addition, all patients were described to have a biventricular connection. ${ }^{6}$

Because quite often in the initial postoperative condition after a Fontan-type operation for a univentricular circulation, volume suppletion and vasoactive treatment are needed, there is a need for availability of cardiac output information. ${ }^{3}$ In this regard we applied combined epi-aortic cardiac output measurement with Fick measurements as the gold standard in patients with a univentricular circulation after a Fontan-type operation. . $^{1,7}$ 


\section{Materials and methods Patients}

In eight patients operated to construct a total cavo-pulmonary connection for a univentricular cardiac anomaly (1 female, 7 males, mean age 2 years 7 months, range 6 months to 4 years 2 months), materials and equipment for epi-aortic cardiac output measurement were available and three intraoperative sequential measurements with a five minute interval were done and compared to Fick calculations of the cardiac output. The parents of the patients were informed and consented to the operative treatment including the cardiac output measurements.

Because for the epi-aortic catheter technique, the measurement of the aortic luminal diameter is an essential part of the method, the epi-aortic Doppler measurement of the aortic diameter was compared to the diameter as derived from cardiac catheterization as well.

\section{Epi-aortic cardiac output measurement}

For epi-aortic or extravascular measurements of cardiac output and aortic diameter, EVD probes (Applied Biometrics, Burnsville, MN, USA) connected to the Abcom 2000 cardiac output computer (Applied Biometrics) were used as described previously. ${ }^{6}$ According to the information of the manufacturer, this Doppler method should be limited to vessels up to 20 millimeter in diameter, because of limitations of the ultrasound technology of the device. The device was intraoperatively placed onto the aorta after termination of cardiopulmonary bypass. Care was taken to position the probe centrally on the ascending aorta. The catheter was put through a drain hole, so that no additional exit wound had to be made. After completion of surgery, just before leaving the operating room (after up to 1.5 hours) the ingenious technique of removal was also applied as described. ${ }^{6}$ No complications were registered in relation to the epi-aortic cardiac output measurement.

\section{Fick method}

In order to calculate the cardiac output, a Siemens 900C ventilator (Siemens, Solna, Sweden) was connected to an MBM-100 Deltatrec metabolic computer (Datex-Ohmeda, Helsinki, Finland) in a closed system, with the use of cuffed endo-tracheal tubes. Intake of $\mathrm{O}_{2}\left(\mathrm{VO}_{2}\right.$ in $\left.1 . \mathrm{min}^{-1}\right)$ was set on the ventilator. The arterial and mixed venous partial pressure and saturation of $\mathrm{O}_{2}\left(\mathrm{PaO}_{2}\right.$ and $\mathrm{PvO}_{2}$ in mmol.1 ${ }^{-1}, \mathrm{SaO}_{2}$ and $\mathrm{SvO}_{2}$ in \%) as well as the hemoglobin content ( $\mathrm{Hb}$ in mmol. $1^{-1}$ ) were done as routine laboratory measurements. When necessary their units were adjusted to fit into the Fick formula.
None of the patients showed signs of residual intracardiac or pulmonary shunts after surgery. All of them had arterial and transcutaneous oxygen saturations of $100 \%$ at the time of the Fick measurements.

\section{Statistical methods}

Variables are reported as mean with range. Regression analysis was done for both the cardiac output data as well as for the diameter measurements. A p-value of smaller than 0.05 was regarded as significant. A Bland-Altman plot for the two methods of cardiac output measurement was constructed. ${ }^{8}$

\section{Results}

Epi-aortic measurement of the aortic diameter resulted in mean diameter of $18 \mathrm{~mm}$ (range 14 to 25). Angiographic measurement showed a mean diameter of the $17 \mathrm{~mm}$ (range 10 to 24). One patient after a Damus-Kaye-Stansel ${ }^{9}$ reconstruction of the arterial outlet of the univentricular heart had a diameter by epi-aortic measurement of $25 \mathrm{~mm}$ and by angiography of $24 \mathrm{~mm}$. The correlation coefficient for the two methods was calculated as $0.88(\mathrm{p}<0.05)$ with a systematically larger result for the Abcom 2000 diameters (Figure 1).

The Abcom 2000 measurements resulted in a mean cardiac output of $2.81 . \mathrm{min}^{-1}$ (range 1.2 to 6.3). A slight increase was found in the three clusters of measurement, 2.7 (range 1.2 to 5.5 ), 2.8 (range 1.3 to 6.3 ), 2.9 (1.3 to 6.3) $1 . \mathrm{min}^{-1}$. The Fick calculations resulted in a mean cardiac output of $1.81 . \mathrm{min}^{-1}$ (range 0.8 to 5.0), a slight increase was found in the three clusters of measurement as well, 1.4 (0.8 to 2.2), 1.9 (0.8 to 5.0), 2.0 (0.8 to 4.2) $1 . \mathrm{min}^{-1}$. The correlation coefficient between the Abcom 2000 results and the Fick data could be calculated as $0.11(\mathrm{p}<0.05)$ (Figure 2).

Leaving out the one patient with an aortic diameter of $25 \mathrm{~mm}$ by angiography and $24 \mathrm{~mm}$ by epi-aortic measurement of the aorta as advised in the information from the manufacturer,



$y=0.7769 x+4.9767$ $R^{2}=0.88$

Figure I Measurement of aortic diameter. 


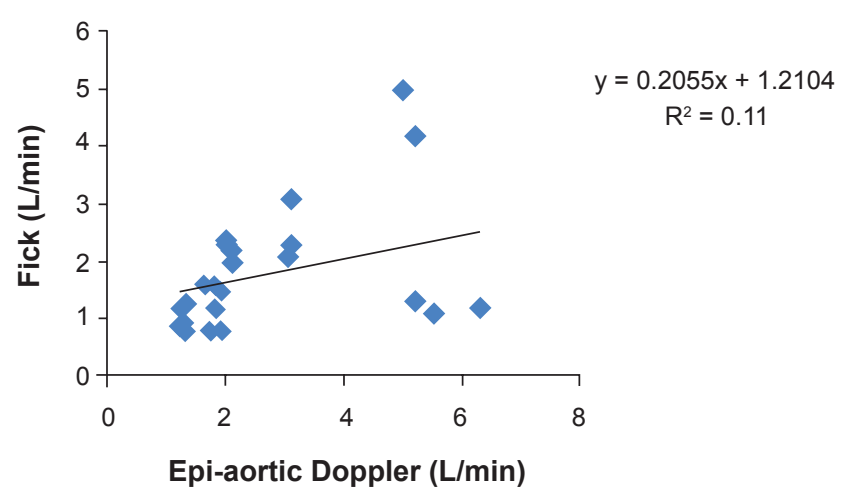

Figure 2 Cardiac output (all patients).

the correlation coefficient improved to $0.55(\mathrm{p}<0.05)$ (Figure 3). These findings were supported by Bland-Altman plotting (Figure 4).

\section{Discussion}

After Fontan-type operations, cardiac output measurements by Swan-Ganz methodology are not possible. In this setting even the gold standard of the Fick method should regarded critically, because even in the absence of a residual intracardiac shunt, there may be a considerable collateral aortopulmonary circulation. In this setting the method of extravascular or epi-aortic Doppler measurement was applied after Fontan surgery.

Although the number of observations were restricted to eight patients, due to limited availability of the device, epi-aortic Doppler measurement of cardiac output could be applied in aortas up to 20 millimeter in diameter. A reasonable correlation with Fick calculations was found. The method is intrinsically invasive, nevertheless application

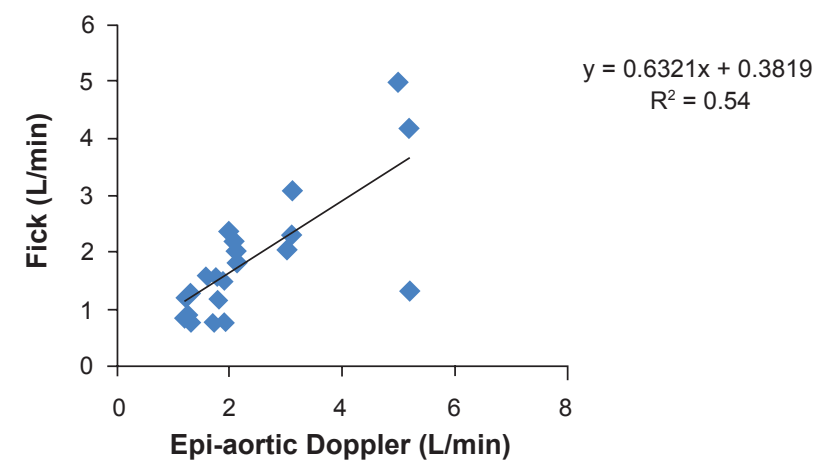

Figure 3 Cardiac output (aorta $<20 \mathrm{~mm}$ ).

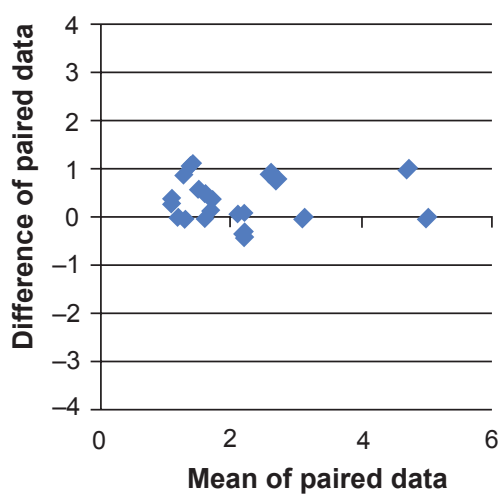

Cardiac output by epi-aortic Doppler and by Fick method

Figure 4 Bland-Altman plot.

and removal of the device were easy and no complications related to the system were observed. An important restriction is the often present abnormal anatomy, either congenitally or after surgery.

\section{Disclosure}

The authors report no conflicts of interest in this work.

\section{References}

1. Franch RH, Douglas JS, King SB III, Kern MJ. Cardiac catheterization, coronary angiography, and coronary bloodflow and pressure measurements. In: Fuster V, Alexander RW, O’Rourke RA, Roberts R, King SB III, Wellens HJJ, editors. Hurst's The Heart. 10th edition. New York: McGraw-Hill; 2001. p. 479-524.

2. Seiler C, DiMario C. Invasive imaging and haemodynamics. In: Cam AJ, Lüscher TF, Serruys PW, editors. ESC Textbook of Cardiovascular Medicine. Malden: Blackwell; 2006. p. 159-188.

3. Barnea O, Santamore WP, Rossi A, Salloum E, Chien S, Austin EH Estimation of oxygen delivery in newborns with a univentricular circulation. Circulation. 1998;98:1407-1413.

4. Hoffman GM, Ghanayem NS, Kampine JM, et al. Venous saturation and the anaerobic threshold in neonates after the Norwood procedure for hypoplastic left heart syndrome. Ann Thorac Surg. 2000;70:1515-1521.

5. Peterson RJ, Kissoon N, Murphy SP, et al. Comparison of transtracheal and extravascular Doppler determinations of stroke volume and cardiac output at various states of volume loading in piglets. Crit Care Med. 1995;23:2015-2022.

6. Lequier LL, Leonard SR, Nikaidoh H, Lemler MS, Ramaciotti C. Extravascular Doppler measurement of cardiac output in infants and children after operations for congenital heart disease. J Thorac Cardiovasc Surg. 1999; 117:1223-1225.

7. Coats AJ. Doppler ultrasonic measurement of cardiac output: reproducibility and validation. Eur Heart J. 1990;11(Suppl):49-61.

8. Bland JM, Altman DG. Statistical methods for assessing agreement between two methods of clinical measurement. Lancet 1986;1:307-310.

9. Kouchoukos NT, Blackstone EH, Doty DB, Hanley FL, Karp RB. Kirklin/Barratt-Boyes Cardiac Surgery. 3rd edition. Philadelphia: Churchill Livingstone; 2003. p. 1439-1508. 
